\title{
PENGARUH PERILAKU DAN KEPATUHAN PERAWAT TERHADAP PENGGUNAAN ALAT PELINDUNG DIRI DALAM PENCEGAHAN INFEKSI NOSOKOMIAL DI RUANG RAWAT INAP RSUD Dr. R. M DJOELHAM BINJAI TAHUN 2020
}

\section{ASSOCIATED NURSER BEHAVIOUR AND COMPLIANCE WITH THE USE OF SELF- PROTECTIVE EQUIPMENT IN PREVENTION OF NOSOCOMIAL INFECTIONS IN INPATIENT ROOM Dr. R. M DJOELHAM BINJAI IN 2020}

\author{
Seally Rahmatilah, ${ }^{1}$ Asriwati $^{2}$ Jamaluddin $^{3}$ \\ ${ }^{1}$ Mahasiswa Pascasarjana IKM Fakultas Kesehatan Masyarakat, Institut Kesehatan Helvetia, \\ Medan, Indonesia \\ ${ }^{2}$ Dosen IKM Fakultas Kesehatan Masyarakat, Institut Kesehatan Helvetia, Medan,Indonesia \\ ${ }^{3}$ Dosen IKM Fakultas Kesehatan Masyarakat, Institut Kesehatan Helvetia, Medan,Indonesia \\ *Penulis Korespondensi: seally2609@gmail.com ${ }^{1}$, asriwati033@gmail.com², \\ drjamaluddinmars@gmail.com ${ }^{3}$
}

\begin{abstract}
Abstrak
Rumah sakit tidak hanya menjadi tempat pengobatan, tetapi bisa juga menjadi sarana pelayanan kesehatan yang dapat menjadi sumber infeksi bagi orang lain. Infeksi yang terjadi di rumah sakit disebut infeksi nosokomial. Infeksi nosokomial dapat berasal dari proses penyebaran di pelayanan kesehatan, baik pasien, petugas kesehatan, pengunjung, maupun sumber lainnya. Upaya pencegahan infeksi nosokomial dilakukan terhadap pasien dan tenaga pelayanan kesehatan. Kewaspadaan standar tenaga pelayanan kesehatan adalah kebersihan tangan, penggunaan alat pelindung diri (APD).

Jenis penelitian adalah kuantitatif dengan rancangan cros sectional study. Penelitian ini dilaksanakan di RSUD DR. R. M Djoelham Kota Binjai. Populasi penelitian ini adalah perawat rawat inap RSUD DR. RM Djoelham Kota Binjai, pengambilan sampel yaitu Propotional Random Sampling sebanyak 57 orang.

Berdasarkan hasil analisa bivariat didapatkan bahwa nilai $\mathrm{p}$-value $<0,05$ yaitu pengetahuan (0,651), sikap (0,013), tindakan (0,001), kepatuhan (0,044) di RSUD DR. R.M Djoelham Kota Binjai 2020. Berdarkan hasil multivariat variabel yang paling berpengaruh terhadap penggunaan alat pelindung diri dengan nilai 25,824 yang berarti perawat yang tindakan baik cenderung akan menggunakan alat pelindung diri 25,824 dibanding perawat yang tindakan baik. Dengan hasil penelitian ini diharapakan kepada Kepada pihak manajemen RSUD DR. M Djoelham Kota Binjai untuk meningkatkan perilaku dan kepatuhan dalam penggunaan APD dalam pencegahan infeksi nosokomial dapat melalui pelatihan dan diskusi pada pertemuan dengan perawat.
\end{abstract}

Kata Kunci: Pengetahuan, Sikap, Tindakan, Kepatuhan, Alat Perlindung Diri 


\section{ABSTRACT \\ ASSOCIATED NURSER BEHAVIOUR AND COMPLIANCE WITH THE USE OF SELF- PROTECTIVE EQUIPMENT IN PREVENTION OF NOSOCOMIAL INFECTIONS IN INPATIENT ROOM Dr. R. M DJOELHAM BINJAI IN 2020}

The hospital is not only a place of treatment, but can also be a means of health care that can be a source of infection for other people. Infections that occur in the hospital are called nosocomial infections. Nosocomial infections can originate from the process of spreading in health services, whether patients, health workers, visitors or other sources. Efforts to prevent nosocomial infections are carried out on patients and health service personnel. Standard precautions for health service personnel are hand hygiene, use of personal protective equipment (PPE).

This study was quantitative with a Cross-Sectional design. This research was conducted at DR. R. M Djoelham hospital with population all were inpatient nurses, and the sample was proportional random sampling of 57 people.

Based on the results of the bivariate analysis, it was found that the p-value <.05, namely knowledge (.651), attitude (.013), action (.001), compliance (.044) in DR. R.M Djoelham hospital. Based on the multivariate results the most influential variable was the use of personal protective equipment with a value of 25.824, which means that nurses who took good action tend to use 25.824 personal protective equipment compared to nurses who act well.

The results of this study, it is hoped that the management of DR. M Djoelham Hospital Binjai improving behaviour and compliance in using PPE in the prevention of nosocomial infections can be through training and discussions at meetings with nurses.

Keywords $\quad$ : Knowledge, Attitude, Action, Compliance, Self-Protection Tool 


\section{PENDAHULUAN}

Rumah sakit adalah sarana kesehatan yang menyelenggarakan pelayanan kesehataan secara merata dengan mengutamakan upaya penyembuhan penyakit dan pemulihan kesehatan, yang dilaksananakan secara serasi dan terpadu dengan upaya peningkatan kesehatan dan pencegahan penyakit dalam suatu tatanan rujukan, serta dapat dimanfaatkan untuk pendidikan tenaga dan penelitian. Rumah sakit juga merupakan institusi yang dapat memberi keteladanan dalam budaya hidup bersih dan sehat serta kebersihan lingkungan (1).

Rumah sakit tidak hanya menjadi tempat pengobatan, tetapi bisa juga menjadi sarana pelayanan kesehatan yang dapat menjadi sumber infeksi bagi orang lain. Infeksi yang terjadi di rumah sakit disebut infeksi nosokomial. Infeksi nosokomial dapat berasal dari proses penyebaran di pelayanan kesehatan, baik pasien, petugas kesehatan, pengunjung, maupun sumber lainnya. Kejadian infeksi nosokomial sangat berpengaruh terhadap kondisi kesehatan pasien (8).

Upaya pencegahan infeksi nosokomial dilakukan terhadap pasien dan tenaga pelayanan kesehatan. Kewaspadaan standar tenaga pelayanan kesehatan adalah kebersihan tangan, penggunaan alat pelindung diri (APD). Alat pelindung diri merupakan suatu alat yang dipakai untuk melindungi diri atau tubuh terhadap bahaya-bahaya kecelakaan kerja, dimana secara teknis dapat mengurangi tingkat keparahan dari kecelakaan kerja yang terjadi. Peralatan pelindung diri tidak menghilangkan atau pun mengurangi bahaya yang ada. Peralatan ini hanya mengurangi jumlah kontak dengan bahaya dengan cara penempatan penghalang antara tenaga kerja dengan bahaya (2).

Peningkatkan mutu pelayanan rumah sakit harus dilakukan oleh semua jajaran manajemen rumah sakit, salah satunya adalah tenaga perawat dalam memberikan asuhan keperawatan. Perawat merupakan salah satu pemberi layanan kesehatan yang menjadi pelaksana utama pencegahan 
Journal of Healthcare Technology and Medicine Vol. 6 No. 2 Oktober 2020

Universitas Ubudiyah Indonesia

e-ISSN : 2615-109X 1145

infeksi nosokomial, karena perawat memiliki waktu yang relatif lebih banyak untuk berinteraksi dengan pasien saat melakukan prosedur keperawatan sehingga berpeluang untuk menularkan infeksi kepada pasien (5).

Hasil dari sebuah survei mengenai prevalensi infeksi nosokomial yang dikelola WHO 2002, pada 55 rumah sakit di 14 negara yang dibagi menjadi 4 wilayah yakni, Eropa, Mediteranian Timur, Asia Tenggara dan Pasifik Barat, menunjukkan bahwa sekitar 8,7\% pasien di rumah sakit mengalami infeksi nosokomial, pada survei lain menyatakan lebih dari 1,4 juta pasien diseluruh dunia mengalami infeksi nosokomial. Frekuensi paling tinggi terjadi pada rumah sakit Mediteranian Timur sebesar 11,8\%, diikuti wilayah Asia Tenggara sebesar $11 \%$, kemudian wilayah Pasifik Bara 9,0 \%, dan selanjutnya Eropa sebesar 7,7 \% (10).

Menurut WHO 2008 (63) infeksi nosokomial yang paling umum terjadi dirumah sakit adalah infeksi saluran kencing (40\%), infeksi sehubungan dengan penggunaan alat intravaskular (20\%), pneumonia nosokomial (18\%), infeksi bedah (15\%) dan infeksi nosokomial lainnya.

Berdasarkan data RSUD Dr. R. M Djoelham Kota Binjai bulan Januari sampai Desember 2019 didapatkan angka kejadian nosokomial di Rumah Sakit Djoelham Binjai bahwa angka HAIs pada bulan Januari 2019 sebanyak 8D, yaitu terdapat 1 pasien plebitis. Pada bulan Februari 2019 tidak ditemukan adanya angka HAIs. Pada bulan Maret angka HAIs sebanyak 60, terdapat 1 pasien plebitis. Pada bulan April angka HAIs sebanyak 12ם, ditemukan 3 kejadian plebitis. Pada bulan Mei angka HAIs sebanyak 60, ditemukan 1 kejadian plebitis. Pada bulan Juni angka HAIs

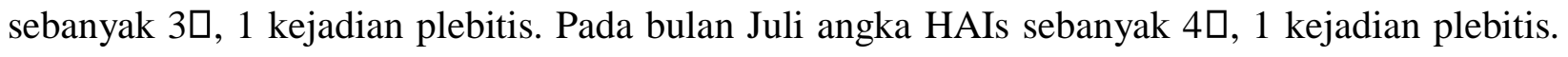
Pada bulan Agustus angka HAIs sebanyak 18ם, ditemukan 1 kejadian plebitis. Pada bulan September 2019 tidak ditemukan adanya angka HAIs. Pada bulan Oktober angka HAIs sebanyak 60, ditemukan 1 kejadian plebitis. Pada bulan November angka HAIs sebanyak 60, ditemukan 1 kejadian plebitis. Pada bulan Desember angka HAIs sebanyak 16D, ditemukan 1 kejadian plebitis. Total keseluruhan sebanyak 12 angka kejadian infeksi nosokomial terjadi peningkatan setiap bulannya.

Berdasarkan penelitian awal yang dilakukan pada 10 Januari 2020 di RSUD Dr. R. M Djoelham Binjai diketahui bahwa masih banyak perawat yang tidak memakai masker dan sarung tangan sebagai APD. Selain itu dari pihak RS diketahui bahwa tidak ada pengawasan dan teguran 
Journal of Healthcare Technology and Medicine Vol. 6 No. 2 Oktober 2020

Universitas Ubudiyah Indonesia

e-ISSN : 2615-109X 1146

pada perawat jika tidak menggunakan APD saat melakukan pelayanan. Banyaknya perawat yang tidak menggunakan menggunakan APD tentu saja sangat berisiko terkena penyakit infeksi nosokomial.

Mengingat pentingnya peran perawat dalam pencegahan infeksi nosokomial maka peneliti tertarik untuk meneliti pengaruh pengetahuan sikap tindakan dan kepatuhan perawat terhadap penggunaan alat pelindung diri dalam pencegahan infeksi nosokomial di Ruang Rawat Inap RSUD Dr. R. M Djoelham Kota Binjai Tahun 2020 .

\section{BAHAN DAN METODE}

Jenis penelitian adalah kuantitatif dengan rancangan cros sectional study. Penelitian kuantitatif dilakukan dengan survey analitik yang bertujuan untuk menganalisa pengaruh pengetahuan, sikap, tindakan dan kepatuhan terhadap penggunaan alat pelindung diri (APD) pada perawat dalam pencegahan infeksi nosokomial di Ruang Rawat Inap RSUD Dr. M Djoelham Kota Binjai. Penelitian ini dilaksanakan di RSUD DR. R. M Djoelham Kota Binjai, yang berlokasi di Jln. Jenderal Gatot Subroto No.9. Penelitian ini dilakukan mulai bulai januari sampai dengan febuari 2020. Populasi penelitian ini adalah perawat rawat inap RSUD DR. RM Djoelham Kota Binjai, pengambilan sampel yaitu Propotional Random Sampling sebanyak 57 orang.

\section{HASIL DAN PEMBAHASAN}

\section{a. Pengaruh Pengetahuan Perawat Terhadap Penggunaan Alat Pelindung Diri Dalam Pencegahan Infeksi Nosokomial}

Untuk mengetahui pengaruh pengetahuan Perawat Terhadap Penggunaan Alat Pelindung Diri Dalam Pencegahan Infeksi Nosokomial Di Ruang Rawat Inap RSUD Dr. R. M Djoelham Binjai Tahun 2020, dapat dilihat pada gambar tabel di bawah ini:

Tabel 4.5 Pengaruh Pengetahuan Perawat Terhadap Penggunaan Alat Pelindung Diri Dalam Pencegahan Infeksi Nosokomial

\begin{tabular}{|c|c|c|c|c|c|c|c|c|}
\hline \multirow{3}{*}{ Pengetahuan } & \multicolumn{6}{|c|}{ Penggunaan APD } & \multirow{3}{*}{ p value } & \multirow{3}{*}{ OR } \\
\hline & \multicolumn{2}{|c|}{$\begin{array}{c}\text { Tidak } \\
\text { Lengkap }\end{array}$} & \multicolumn{2}{|c|}{ Lengkap } & \multicolumn{2}{|c|}{ Total } & & \\
\hline & $\mathbf{n}$ & $\%$ & $\mathbf{n}$ & $\%$ & $\mathbf{n}$ & $\%$ & & \\
\hline Buruk & 2 & 40 & 3 & 60 & 5 & 100 & \multirow{3}{*}{0,651} & \multirow{3}{*}{0,529} \\
\hline Baik & 29 & 55,8 & 23 & 44,2 & 52 & 100 & & \\
\hline Jumlah & 31 & 54,4 & 26 & 45,6 & 57 & 100 & & \\
\hline
\end{tabular}


Journal of Healthcare Technology and Medicine Vol. 6 No. 2 Oktober 2020

Universitas Ubudiyah Indonesia

e-ISSN : 2615-109X 1147

Berdasarkan tabel 4.5 di atas diketahui bahwa perawat yang berpengetahuan buruk sebanyak 2 orang (40\%) tidak menggunakan APD lengkap dan 3 orang (60\%) menggunakan APD lengkap. Sedangkan perawat berpengetahuan baik sebanyak 29 orang $(55,8 \%)$ tidak menggunakan APD lengkap dan 23 orang (44,2\%) menggunakan APD lengkap. Berdasarkan hasil perhitungan uji statistik diperoleh nilai $p$ yaitu $0,651<0,05$ dan OR 0,529 sehingga dapat disimpulkan bahwa tidak ada pengaruh pengetahuan perawat terhadap penggunaan alat pelindung diri dalam pencegahan infeksi nosokomial Di Ruang Rawat Inap RSUD Dr. R. M Djoelham Binjai Tahun 2020.

\section{b. Pengaruh Sikap Perawat Terhadap Penggunaan Alat Pelindung Diri Dalam Pencegahan Infeksi Nosokomial}

Untuk mengetahui pengaruh sikap Perawat Terhadap Penggunaan Alat Pelindung Diri Dalam Pencegahan Infeksi Nosokomial Di Ruang Rawat Inap RSUD Dr. R. M Djoelham Binjai Tahun 2020, dapat dilihat pada gambar tabel di bawah ini:

Tabel 4.6 Pengaruh Sikap Perawat Terhadap Penggunaan Alat Pelindung Diri Dalam Pencegahan Infeksi Nosokomial Penggunaan APD

\begin{tabular}{|c|c|c|c|c|c|c|c|c|c|}
\hline \multirow[t]{2}{*}{ Sikap } & \multicolumn{2}{|c|}{$\begin{array}{c}\text { Tidak } \\
\text { Lengkap }\end{array}$} & \multicolumn{2}{|c|}{ "Lengkap } & \multicolumn{2}{|c|}{ Total } & \multirow{2}{*}{$\begin{array}{l}P \text {-value } \\
\text { Negatif }\end{array}$} & \multirow{2}{*}{$\begin{array}{r}\boldsymbol{O R} \\
\\
14\end{array}$} & \multirow{2}{*}{82,4} \\
\hline & $\bar{n}$ & $\%$ & $\mathrm{n}$ & $\%$ & $\mathrm{n}$ & $\%$ & & & \\
\hline 17,6 & 17 & 100 & 0,013 & 6,314 & & & & & \\
\hline Positif & 17 & 42,5 & 23 & 57,5 & 40 & 100 & & & \\
\hline Jumlah & 31 & 54,4 & 26 & 45,6 & 34 & 100 & & & \\
\hline
\end{tabular}


Journal of Healthcare Technology and Medicine Vol. 6 No. 2 Oktober 2020

Universitas Ubudiyah Indonesia

e-ISSN : 2615-109X 1148

Berdasarkan tabel 4.6 di atas diketahui bahwa perawat yang bersikap negatif sebanyak 14 orang $(82,4 \%)$ tidak menggunakan APD lengkap dan 3 orang $(17,6 \%)$ menggunakan APD lengkap. Sedangkan perawat bersikap positif sebanyak 17 orang (42,5\%) tidak menggunakan APD lengkap dan 23 orang $(57,5 \%)$ menggunakan APD lengkap. Berdasarkan hasil perhitungan uji statistik diperoleh nilai $p$ yaitu $0,013<0,05$ dan OR 6,314 sehingga dapat disimpulkan bahwa ada pengaruh sikap perawat terhadap penggunaan alat pelindung diri dalam pencegahan infeksi nosokomial Di Ruang Rawat Inap RSUD Dr. R. M Djoelham Binjai Tahun 2020.

\section{c. Pengaruh Tindakan Pengetahuan Perawat Terhadap Penggunaan Alat Pelindung Diri Dalam Pencegahan Infeksi Nosokomial}

Untuk mengetahui pengaruh Tindakan Perawat Terhadap Penggunaan Alat Pelindung Diri Dalam Pencegahan Infeksi Nosokomial Di Ruang Rawat Inap RSUD Dr. R. M Djoelham Binjai Tahun 2020, dapat dilihat pada gambar tabel di bawah ini:

Tabel 4.7 Pengaruh Tindakan Perawat Terhadap Penggunaan Alat Pelindung Diri Dalam Pencegahan Infeksi Nosokomial

\begin{tabular}{|c|c|c|c|c|c|c|c|c|}
\hline \multirow{3}{*}{ Tindakan } & \multicolumn{6}{|c|}{ Penggunaan APD } & \multirow{3}{*}{$\underset{\text { value }}{\mathbf{p}}$} & \multirow{3}{*}{ OR } \\
\hline & \multicolumn{2}{|c|}{$\begin{array}{c}\text { Tidak } \\
\text { Lengkap }\end{array}$} & \multicolumn{2}{|c|}{ Lengkap } & \multicolumn{2}{|c|}{ Total } & & \\
\hline & n & $\%$ & $\mathbf{n}$ & $\%$ & $\mathbf{n}$ & $\%$ & & \\
\hline Buruk & 15 & 93,8 & 1 & 6,3 & 16 & 100 & \multirow{3}{*}{0,001} & \multirow{3}{*}{23,438} \\
\hline Baik & 16 & 39,0 & 25 & 61,0 & 41 & 100 & & \\
\hline Jumlah & 31 & 54,4 & 26 & 45,6 & 57 & 100 & & \\
\hline
\end{tabular}

Berdasarkan tabel 4.7 di atas diketahui bahwa perawat yang tindakan buruk sebanyak 15 orang $(93,8 \%)$ tidak menggunakan APD lengkap dan 1 orang (6,3\%) menggunakan APD lengkap. Sedangkan perawat tindakan baik sebanyak 16 orang $(39,0 \%)$ tidak menggunakan APD lengkap dan 25 orang $(61,0 \%)$ menggunakan APD lengkap. Berdasarkan hasil perhitungan uji statistik diperoleh nilai $p$ yaitu $0,001<0,05$ dan OR 23,438 sehingga dapat disimpulkan bahwa ada pengaruh tindakan perawat terhadap penggunaan alat pelindung diri dalam pencegahan infeksi nosokomial Di Ruang Rawat Inap RSUD Dr. R. M Djoelham Binjai Tahun 2020. 


\section{d. Pengaruh Kepatuhan Pengetahuan Perawat Terhadap Penggunaan Alat Pelindung Diri Dalam Pencegahan Infeksi Nosokomial}

Untuk mengetahui pengaruh Kepatuhan Perawat Terhadap Penggunaan Alat Pelindung Diri Dalam Pencegahan Infeksi Nosokomial Di Ruang Rawat Inap RSUD Dr. R. M Djoelham Binjai Tahun 2020, dapat dilihat pada gambar tabel di bawah ini:

Tabel 4.8 Pengaruh Kepatuhan Perawat Terhadap Penggunaan Alat Pelindung Diri Dalam Pencegahan Infeksi Nosokomial

\begin{tabular}{|c|c|c|c|c|c|c|c|c|}
\hline \multirow{3}{*}{ Tindakan } & \multicolumn{6}{|c|}{ Penggunaan APD } & \multirow{3}{*}{$\begin{array}{c}\mathbf{p} \\
\text { value }\end{array}$} & \multirow{3}{*}{ OR } \\
\hline & \multicolumn{2}{|c|}{$\begin{array}{c}\text { Tidak } \\
\text { Lengkap }\end{array}$} & & & \multicolumn{2}{|c|}{ Total } & & \\
\hline & $\mathbf{n}$ & $\%$ & $\mathbf{n}$ & $\%$ & $\mathbf{n}$ & $\%$ & & \\
\hline Buruk & 15 & 93,8 & 1 & 6,3 & 16 & 100 & \multirow{3}{*}{0,001} & \multirow{3}{*}{23,438} \\
\hline Baik & 16 & 39,0 & 25 & 61,0 & 41 & 100 & & \\
\hline Jumlah & 31 & 54,4 & 26 & 45,6 & 57 & 100 & & \\
\hline
\end{tabular}

\section{Lengkap}

Berdasarkan tabel 4.8 di atas diketahui bahwa perawat yang tidak patuh sebanyak 12 orang (80,0\%) tidak menggunakan APD lengkap dan 3 orang (17,6\%) menggunakan APD lengkap. Sedangkan perawat patuh sebanyak 19 orang $(45,2 \%)$ tidak menggunakan APD lengkap dan 23 orang (54,8\%) menggunakan APD lengkap. Berdasarkan hasil perhitungan uji statistik diperoleh nilai $p$ yaitu $0,044<0,05$ dan OR 4,842 sehingga dapat disimpulkan bahwa ada pengaruh kepatuhan perawat terhadap penggunaan alat pelindung diri dalam pencegahan infeksi nosokomial Di Ruang Rawat Inap RSUD Dr. R. M Djoelham Binjai Tahun 2020.

Berdasarkan tabel 4.10 di atas merupakan hasil akhir analisis multivariat dengan uji regresi logistic dan diketahui bahwa variabel tindakan menjadi variabel yang paling berpengaruh terhadap penggunaan APD. Berdasarkan tabel di atas diketahui bahwa overall percentage sebesar 78,9 \% yang berarti bahwa sikap positif, tindakan baik dan patuh dapat mempengaruhi penggunaan APD sebesar 78,9\% sedangkan 21,1\% dipengaruhi oleh faktor lain yang tidak diteliti.

Berdasarkan hasil penelitian diketahui bahwa perawat yang berpengetahuan baik sebanyak 23 orang $(44,2 \%)$ menggunakan APD lengkap dan 29 orang (55,8\%) tidak menggunakan APD lengkap, sedangkan perawat yang berpengetahuan buruk sebanyak 3 orang $(60 \%)$ menggunakan 
Journal of Healthcare Technology and Medicine Vol. 6 No. 2 Oktober 2020

Universitas Ubudiyah Indonesia

e-ISSN : 2615-109X 1150

APD lengkap dan 2 orang (40\%) tidak menggunakan APD lengkap. Dari hasil analisis uji fisher exact test antara pengetahuan dengan penggunaan APD diperoleh nilai $\mathrm{p}=0,651<(0,05)$, maka dapat disimpulkan bahwa tidak ada hubungan antara pengetahuan dengan penggunaan APD.

Sebagian besar perawat di RSUD Dr. R.M. Djoelham Binjai berpengetahuan baik. Penelitian ini sejalan dengan Fahmi yang mendapatkan bahwa sebagian besar perawat di RS berpengetahuan baik. Pengetahuan yang dimiliki perawat dipengaruhi oleh karakteristik responden yang meliputi pendidikan dan masa kerja. Pada penelitian ini perawat di RSUD Dr.R.M. Djoelham Binjai berpendikan D-III dan S-1 di RSUD Dr. R. M Djoelham Binjai lebih dari 1 tahun. Pendidikan yang tinggi dan masa kerja yang lama dapat berpengaruh terhadap pengetahuan perawat tentang penggunaan APD (61).

Peningkatan pengetahuan dan keterampilan perawat tentang penggunaan APD untuk mencegah infeksi nosokomial dapat dilakukan dengan melakukan pelatihan bagi perawat. Hal ini sesuai dengan Habni yang mendapatkan bahwa $76 \%$ perawat yang tidak mendapat pelatihan tentang pencegahan infeksi nosokomial cenderung memiliki perilaku yang tidak sesuai dalam melakukan infeksi nosokomial (3).

Materi yang diperlukan untuk meningkatkan pengetahuan perawat di RSUD Dr. R.M. Djoelham Binjai berupa materi tentang dampak dan resiko jika tidak menggunakan APD dan APD yang digunakan tidak steril atau digunakan berkali-kali untuk melayani pasien yang berbeda-beda. Peningkatan pengetahuan perawat ini dapat dilakukan pada saat pertemuan dengan perawat yang ada di RSUD Dr. R. M Djoelham Binjai maupun perawat lainnya.

Sikap adalah suatu kecenderungan untuk memberikan respon terhadap suatu obyek atau sekumpulan obyek dalam bentuk perasaan memihak (favourable) maupun tidak memihak (unfavourable) melalui proses interaksi komponen komponen sikap yaitu kognitif (pengetahuan), afektif (perasaan) dan konatif (kecenderungan mendukung terhadap upaya kesehatan.

Berdasarkan hasil penelitian diketahui bahwa perawat yang bersikap positif sebanyak 23 orang (57,5\%) menggunakan APD dan 17 orang (42,5\%) tidak menggunakan APD, sedangkan perawat yang bersikap negatif sebanyak 3 orang $(8,3 \%)$ menggunakan APD dan 14 orang $(82,4 \%)$ tidak menggunakan APD. Dari hasil analisis uji Continuity Correction antara sikap dengan penggunaan APD diperoleh nilai $\mathrm{p}=0,013$, Karena nilai $\mathrm{p}(0,013)<\alpha(0,05)$, maka dapat disimpulkan bahwa ada hubungan antara sikap dengan penggunaan APD dengan OR $=6,314$ yang 
Journal of Healthcare Technology and Medicine Vol. 6 No. 2 Oktober 2020

Universitas Ubudiyah Indonesia

e-ISSN : 2615-109X 1151

berarti bahwa perawat yang bersikap positif cenderung akan menggunakan APD 6,314 kali dibanding perawat yang bersikap negatif.

Menurut asumsi peneliti, dari hasil penelitian diketahui bahwa sikap tenaga medis sudah positif, tetapi masih ada beberapa tenaga medis yang memiliki sikap negatif hal ini didasari oleh masih banyak perawat tidak mencuci tangan, tidak menggunakan sarung tangan, penanganan benda tajam yang salah, teknik dekontaminasi yang tidak adekuat, dan kurangnya sumber daya untuk melaksanakan prisip Universal Precaution. Sikap negatif perawat Djoelham disebakan karena merasa interaksinya dengan pasien terbatasi dan prosedur penggunaan APD yang membutuhkan waktu.

Berdasarkan hasil penelitian diketahui bahwa perawat yang tindakan baik sebanyak 25 orang (61,0\%) menggunakan APD lengkap dan 16 orang (39,0\%) tidak menggunakan APD lengkap, sedangkan perawat yang tindakan buruk patuh sebanyak 1 orang $(6,3 \%)$ menggunakan APD lengkap dan 15 orang $(93,8 \%)$ tidak menggunakan APD lengkap. Dari hasil analisis uji Continuity Correction antara tindakan dengan penggunaan APD diperoleh nilai $\mathrm{p}=0,001$ dan $\mathrm{OR}=23,438$, Karena nilai $\mathrm{p}(0,001)<\alpha(0,05)$, maka dapat disimpulkan bahwa ada hubungan antara tindakan dengan penggunaan APD dengan $\mathrm{OR}=23,438$ yang berarti bahwa perawat yang tindakan baik cenderung akan menggunakan APD 23,438 kali dibanding perawat yang tindakan buruk.

Sebagian besar perawat Djoelham tidak mencuci tangan sebelum kontak dengan pasien dan lingkungan rumah sakit. Mereka menganggap waktu yang paling penting untuk mencuci tangan adalah setelah kontak dengan pasien dan lingkungan rumah sakit, walaupun tidak semua responden yang melaksanakannya.

Berdasarkan Djojosugito cuci tangan merupakan bagian dari universal precaution yang sangat penting untuk dilakukan bagi seluruh petugas kesehatan khususnya perawat. Perawat sangat berperan dalam pengendalian infeksi nosokomial terutama dalam menekan angka kejadian infeksi nosokomial di RSUD Dr. R. M Djoelham Binjai. Dari penelitian tersebut jelas dikatakan bahwa perawat sangat berperan dalam menekan terjadinya angka infeksi nosokomial namun juga sebaliknya, perawat dapat berperan dalam meningkatkan angka kejadian infeksi nosokmial di rumah sakit (47).

Penggunaan alat pelindung diri akan mengurangi kemungkinan pekerja kontak dengan infeksius yang menginfeksi klien. Hasil observasi menunjukkan bahwa sebagian perawat memakai sarung tangan untuk kontak dengan darah/cairan tubuh yakni $71 \%$. Hal ini tidak sejalan dengan 
Journal of Healthcare Technology and Medicine Vol. 6 No. 2 Oktober 2020

Universitas Ubudiyah Indonesia

e-ISSN : 2615-109X 1152

hasil penelitian yang dilakukan oleh Arenas dkk yang menemukan mayoritas perawat memakai sarung tangan untuk kontak dengan darah/cairan tubuh yakni 92,9\% (52). Tujuan penggunaan sarung tangan adalah menurunkan resiko terkontaminasinya tangan pelayan kesehatan terhadap darah dan cairan tubuh lainnya . Hal ini menunjukkan bahwa sebagian penggunaan sarung tangan untuk kontak dengan cairan tubuh klien tidak dilakukan oleh perawat (63).

Berdasarkan hasil penelitian diketahui bahwa perawat yang patuh sebanyak 23 orang (54,8\%) menggunakan APD lengkap dan 19 orang (45,2\%) tidak menggunakan APD lengkap, sedangkan perawat yang tidak patuh sebanyak 3 orang $(17,6 \%)$ menggunakan APD lengkap dan 12 orang $(80,0 \%)$ tidak menggunakan APD lengkap. Dari hasil analisis uji Continuity Correction antara kepatuhan dengan penggunaan APD diperoleh nilai $\mathrm{p}=0,044$ dan $\mathrm{OR}=4,842$, Karena nilai $\mathrm{p}(0,044)<\alpha(0,05)$, maka dapat disimpulkan bahwa ada hubungan antara kepatuhan dengan penggunaan APD dengan $\mathrm{OR}=4,842$ yang berarti bahwa perawat yang patuh cenderung akan menggunakan APD 4,842 kali dibanding perawat yang tidak patuh. Berdasarkan analisis multivariat diketahui bahwa variabel kepatuha adalah faktor yang paling memengaruhi penggunaan APD.

Dalam penelitian ini isolasi sosial dapat dilihat dari jawaban responden pada pertanyaan tentang teman selalu mengingatkan untuk menggunakan APD, mengikuti anjuran untuk menggunakan APD. Berdasarkan hasil penelitian diketahui bahwa sebagian besar perawat menjawab tidak sehingga dapat diketahui bahwa isolasi sosial pada perawat di RSUD Dr. R. M Djoelham Binjai masih kurang. Faktor lain yang memengaruhi kepatuhan adalah motivasi. Motivasi dapat diperoleh dari diri sendiri dan lingkungan. Dalam penelitian ini motivasi dapat dilihat dari pertanyaan tentang ada perbedaan pemakaian APD saat melakukan tindakan terhadap pasien dengan penyakit tertentu dan pihak RS menyediakan tempat penyimpanan APD yang sedang dan sudah terpakai secara khusus di ruangan, termotivasi menggunakan APD saat melakukan tindakan keperawatan, berusaha menyediakan sendiri perlengkapan perlindungan diri bila persediaan di RS sudah habis atau tidak ada dan pihak RS memberikan penghargaan (reward) kepada perawat yang menggunakan APD. Berdasarkan hasil penelitian diketahui bahwa sebagian besar perawat menjawab tidak pada pertanyaan tersebut sehingga dapat diketahui bahwa motivasi perawat di RSUD Dr. R. M Djoelham Binjai masih kurang.

\section{Kesimpulan}


1. Tingkat pengetahuan perawat dalam pencegahan infeksi nosokomial sebagian besar berpengetahuan baik sebanyak 23 orang (44,2\%) menggunakan APD lengkap dan 29 orang $(55,8 \%)$ tidak menggunakan APD lengkap, sedangkan perawat yang berpengetahuan buruk sebanyak 3 orang (60\%) menggunakan APD lengkap dan 2 orang (40\%) tidak menggunakan APD lengkap. Hal ini menunjukan bahwa perawat sudah memiliki pengetahuan baik.

2. Sikap perawat dalam pencegahan infeksi nosokomial yang bersikap positif sebanyak 23 orang (57,5\%) menggunakan APD dan 17 orang (42,5\%) tidak menggunakan APD, sedangkan perawat yang bersikap negatif sebanyak 3 orang $(8,3 \%)$ menggunakan APD dan 14 orang $(82,4 \%)$ tidak menggunakan APD. Ada pengaruh sikap perawat terhadap penggunaan APD dalam pencegahan infeksi nosokomial. Perawat yang bersikap positif cenderung menggunakan APD.

3. Tindakan perawat dalam pencegahan infeksi nosokomial yang memiliki tindakan baik sebanyak 25 orang $(61,0 \%)$ menggunakan APD lengkap dan 16 orang $(39,0 \%)$ tidak menggunakan APD lengkap, sedangkan perawat yang tindakan buruk patuh sebanyak 1 orang (6,3\%) menggunakan APD lengkap dan 15 orang $(93,8 \%)$ tidak menggunakan APD lengkap. Ada pengaruh Tindakan perawat terhadap penggunaan APD dalam pencegahan infeksi nosokomial.

4. Kepatuhan perawat dalam pencegahan infeksi nosokomial yang patuh sebanyak 23 orang $(54,8 \%)$ menggunakan APD lengkap dan 19 orang $(45,2 \%)$ tidak menggunakan APD lengkap, sedangkan perawat yang tidak patuh sebanyak 3 orang $(17,6 \%)$ menggunakan APD lengkap dan 12 orang $(80,0 \%)$ tidak menggunakan APD lengkap. Ada pengaruh Kepatuhan perawat terhadap penggunaan APD dalam pencegahan infeksi nosokomial. Perawat yang patuh cenderung akan menggunakan APD. Kepatuhan perawat dipengaruhi oleh budaya keselamatan kerja yang dibangun belum positif.

5. Berdasarkan analisis multivariat melalui uji regresi logistik diketahui variabel tindakan $(0,005)$ merupakan variabel yang berkontribusi terbesar memengaruhi perawat dalam penggunaan APD dalam pencegahan infeksi nosokomial di RSUD Dr. R. M Djoelham Kota Binjai 2020.

\section{Saran}

1. Kepada Pihak RSUD Dr. R. M Djoelham Binjai 
a. Kepada pihak manajemen RSUD Dr. R. M Djoelham Kota Binjai untuk meningkatkan perilaku dan kepatuhan dalam penggunaan APD dalam pencegahan infeksi nosokomial dapat melalui pelatihan dan diskusi pada pertemuan dengan perawat.

b. Kepada tim tenaga kesehatan untuk mengenal dan mengetahui potensi bahaya penyakit infeksi nosokomial dan pentingnya penggunaan APD.

c. Melakukan pengawasan yang lebih ketat terhadap proses pelaksanaan dari setiap kebijakan yang terkait dengan Pencegahan dan Pengendalian Infeksi di Rumah Sakit dan terus meningkatkan kapasitas tim PPI mengingat masa terbentuknya yang masih baru.

d. Mengingatkan keluarga pasien agar bekerjasama dengan pihak RS dalam menjaga kebersihan lingkungan rumah sakit.

e. Fasilitas berupa sabun desinfektan, masker maupun handscoon sebaiknya terjaga ketersediannya.

f. Media informasi dan promosi pencegahan infeksi di rumah sakit yang telah tersedia baik poster, leaflet, dan booklet, tetap terjaga ketersediaannya agar informasi akan selalu ada setiap saat.

2. Bagi di Institut Kesehatan Helvetia

Agar dapat dijadikan bahan bacaan dan referensi tentang pengaruh perilaku dan kepatuhan perawat terhadap penggunaan APD dalam pencegahan infeksi nosokomial di RSUD Dr. R. M Djoelham Kota Binjai.

3. Bagi Penulis

Agar dapat menambahkan variabel yang berhubunga dengan pengaruh perilaku dan kepatuhan perawat terhadap penggunaan APD dalam pencegahan infeksi nosokomial di RSUD Dr. R. M Djoelham Kota Binjai.

\section{DAFTAR PUSTAKA}

1. Depkes RI. Pedoman Pencegahan Pengendalian. 2019.

2. Suma'mur, P. K. Higene Perusahaan dan Kesehatan Kerja. Jogjakarta: Sagung Seto. 2019.

3. Habni, Y. Perilaku Perawat dalam Pencegahan Infesksi Nosokomial di rindu A, rindu B, rawat jalan di Rumah Sakit Umum Pusat H. Adam Malik Medan. Skripsi FKM USU Medan. 2019.

4. Patricia, Potter. Buku Ajar Fundamental Keperawatan Edisi 4. Jakarta: EGC. 2015.

5. Darmadi. Infeksi Nosokomial Proble, atika dan Pengendalianya. Jakarta: Salemba Medik. 2015. 
Journal of Healthcare Technology and Medicine Vol. 6 No. 2 Oktober 2020

Universitas Ubudiyah Indonesia

e-ISSN : 2615-109X 1155

6. Panjaitan. Manajemen Keperawatan diruang Rawat. Jakarta: Sagung Seto. 2011. 7. Nurmantono. Infeksi Rumah Sakit.http: Infeksi/com/HIV/articles. 2005

8. Septriari, B. B. Infeksi Nosokomial. Yogjakarta: Nuha Medika. 2012.

9. Tientjen, L. Panduan Pencegahan Infeksi untuk Fasilitas Pelayanan Kesehatan dengan Sumber Daya Terbatas. Jakarta: Yayasan Bina Pustaka. 2004.

10. WHO. Prevention Of Hospital-Acquired Infections. 2002.

11. Notoatmodjo, S. Promosi Kesehatan dan Ilmu Perilaku. Jakarta: Rineka Cipta. 2007.

12. Wahid, I. Promosi Kesehatan. Yogyakarta: Graha Ilmu. 2007.

13. Sarwono. Sosiologi Kesehatan. Yogyakarta: Gadjah Mada University Press. 2002.

14. Niven, N. Psikologi Kesehatan Pengantar Untuk Perawat dan Profesional. Jakarta: EGC. 2008.

15. Depnakertrans RI. Pengawasan K3 Lingkungan Kerja, Ditjen Pembinaan Pengawasan Ketenagakerjaan. Jakarta. 2004.

16. Suardi. Manajemen Keperawatan dengan Pendekatan Praktis. Jakarta: Erlangga. 2005.

17. Brooker. Eksiklopedia Keperawatan Edisi Bahasa Indonesia. Jakarta: EGC. 2008.

18. Gruendemann, G. Buku Ajar Keperawatan Preoperatif. Jakarta: EGC. 2005

19. Irianto. Pencegahan Infeksi Nosokomial di Rumah Sakit. Yogyakarta: Kanisius. 2010.

20. Salawati, L. Taufik, N. Putra A. Analisis Tindakan Keselamatan dan Kesehatan Kerja Perat Dalam Pengendalian Infeksi Nosokomial Di Ruang ICU RSUD DR. Zainoel Abidin Banda Aceh. Jurnal Kedokteran Syiah Kuala. 2014: 14(3).

21. Sari, E. Satyabakti, P. Perbedaan Risiko Infeksi Nosokomial Saluran Kemih Berdasarkan Katerisasi Urin, Umur, dan Diabetes Melitus. Jurnal Berkala Epidemiologi Fakultas Kesehatan Masyarakat Universitas Airlangga. 2015: 3(2):205-216.

22. Masloman, A. Kandou, G. Tilaar CH, Analisi Pelaksanaan Pencegahan dan Pengendalian Infeksi Di Kamar Operasi RSUD DR Sam Ratulangi Tondano. Jurnal Pasca Sarjana Ilmu Kesehatan Masyarakat Universitas Sam Ratulangi Manado. 2015: 5(2).

23. Green, W, Lawrence.et.al, Helath Education Planing A Diagnostik Approach, The Johns Hapkins University: Mayfield Publishing Company: 2005.

24. Muhammad I. Panduan Penyusunan Karya Tulis Ilmiah Bidang Kesehatan Menggunakan Metode Ilmiah Hal 92-98. GEN, Bandung Citapustaka Media Perintis. 2016.

25. Notoatmodjo, S. Kesehatan Masyarakat Ilmu dan Seni. Jakarta.Rineka Cipta: 2015.

26. Shetty, N. Infectious Disease: Pathogenesis, Prevention and Case Studies. Wiley Publisher. 2009.

27. Saene, H. K. F. Infection control in the intensive care unit. 2005.

28. Hastono, S. P. Analisis Data Kesehatan. Depok : Fakultas Kesehatan Masyarakat Universitas Indonesia. 2007.

29. Tietjen, L. Panduan Pencegahan Infeksi Untuk Fasilitas Pelayanan Kesehatan Dengan Sumber Daya Terbatas. Yayasan Bina Pustaka Sarwono Prawirohardjo. Jakarta. 2004.

30. Abdullah, K. Sidin, A, I. Pasinringi, S, A. Hubungan Penegetahuan Motivasi dan Supervisi Dengan Kinerja Pencegahan Infeksi Nosokomial Di RSUD Haji Makassar. Jurnal Bagian Manajemen Rumah Sakit Fakultas Kesehatan Masyarakat Universitas Hasanuddin. 2012. 
31. Kartika, S. Hariyanti, T. Pujiastuti, L. Faktor Sumber Daya Manusia dan Komitmen Manajemen yang Mempengaruhi Surveillance Infeksi Nosokomial Di Rumah Sakit Paru Batu. Program Studi Magister Mnajemen Rumah Sakit Fakultas Kedokteran Universitas Brawijaya Malang. 2015: 28(2).

32. Puspasari, Y. Hubungan Pengetahuan, Sikap Dengan Praktik Perawat Dalam Pencegahan Infeksi Nosokomial Di ruang Rawat Inap Rumah Sakit Islam Kendal. 2015: 8(1): 24-43.

33. Handojo, W, H. Pengetahuan Perawat Tentang Infeksi Nosokomial Di Ruang D2 dan D3 Rumah Sakit Adi Husada Undaan Wetan. Journal Adi Husada. Surabaya. 2015: 1(1).

34. Syahrir, S. Tirmanidhana. Raodhah, S. Bujawati, E. Analisi Pelaksanaan Pencegahan dan Pengendalian Infeksi Nosokomial Di ICU RSUD Labuang Baji. Makassar. 2018: 4(2).

35. Sulistyowati, D. Hubungan Tingkat Pengetahuan Sikap Perawat Tentang Infeksi Nosokomial (INOS) Dengan Perilaku Pencegahan Inos Di Ruang Bedah RSUD DR. Moewardi. Jurnal Keperawatan Global. Surakata. 2016: 1(1).

36. Almahdur, N, A. Analisis Pengendalian Infeksi Nosokomial Dengan Hand Hygiene Di Rumah Sakit Umum Haji. Thesis Universitas Airlangga. Surabaya. 2016.

37. Herlambang, S. Dan Murwani, A. Cara mudah memahami manajemen dan rumah sakit. Yogyakarta. Gosyen publishing. 2012.

38. Undang-undang Republik Indonesia Nomor 44 tahun 2009 Tentang Rumah Sakit. Jakarta. 2009.

39. Peraturan Mentri Kesehatan Republik Indonesia Nomor 56 Tahun 2014 tentang klasifikasi dan perizinan Rumah Sakit. Jakarta. 2014.

40. Sabarguna, B. S. dan Halimun, R. Enterprise Resource Planning di Rumah Sakit. Jakarta. Sagung Seto. 2009.

41. Jati, P. Konsep Dasar tentang Manajemen Rumah Sakit. 2009.

42. Nasution, M, N. Manajemen Jasa Terpadu (Total Service Management), Bogor: PT. Ghalia Indonesia. 2004.

43. Rifiani, N. dan Sulihandri, H. Prinsip-prinsip Dasar Keperawatan. Jakarta. Dunia Cerdas. 2013.

44. Iskandar. Keperawatan prefesional. Jakarta. Penerbit In Media. 2013.

45. Persatuan Perawat Nasional Indonesia. Standar Praktik Keperawatan. Jakarta. 2000.

46. Bady, A.M, dkk. Analisis kinerja perawat dalam pengendalian infeksi nosokomial di IRNAI RS Dr Sarjito. 2007.

47. Djojosugito, A, dkk. Buku manual pengendalian infeksi nosokomial di RS. Jakarta: Johnson Medical Indonesia. 2001.

48. Potter P.A.,\& Perry A.G. Buku ajar fundamental keperawatan konsep, proses, dan praktik (Edisi 4 volume 1). Jakarta: EGC. 2005.

49. Setiawati. Analisis faktor-faktor yang mempengaruhi ketaatan petugas kesehatan melakukan hand hygiene dalam mencegah infeksi nosokomial di ruang perinatologi RSUPN Dr. Cipto Mangunkusumo Jakarta. 2009.

50. Wibowo. Manajemen kinerja. Jakarta: PT Rajagrafindo Persada. 2008.

51. WHO. Prevention of hospital acquired infections. 2002

52. Arenas, M. D. A multicentric survey of the practice of hand hygienein haemodialysis units: factors affecting compliance. 2003. 
53. Earl. C. E. Thai Nursing Student's Knowledge and Health Belief about Aids and the Use of Universal Precautions. AAOHN Journal. 2010.

54. McGovern, P., Vesley, D., Kochevar. Factors affecting Universal Precautions Compliance. Journal of Business and Psychology. 2000.

55. Kermode, M. Complience wWith Universal/Standard Precautions among Helath Care Worker in Rural North India. Journal of AIIC. 2005.

56. Kagan. I. Perceived Knowledge of Blood-borne Pathogens and Avoidance of Contact with Infected Patients. Journal of Nursing Scholarship. 2009.

57. Maja, T. M. M., Precaution Use by Occupational Health Nursing Students during Clinical Placement. Adelaide : Tswane University of Technology. 2009.

58. Pinem, S. Penerapan Kewaspadaan Universal oleh Bidan dan Faktor -faktor yang Berhubungan di Puskesmas Kecamatan Wilayah Jakarta Timur Tahun 2003. Depok : Tesis Fakultas Kesehatan Masyarakat UI. 2003.

59. Sahara, A. Faktor-faktor yang Berhubungan dengan Kepatuhan Perawat dalam Penerapan Kewaspadaan Universal/Kewaspadaan Standar di Rumah Sakit Palang Merah Indonesia Bogor Tahun 2011. Depok : Tesis Fakultas Kesehatan Masyarakat UI. 2011.

60. Siagian, J. Pengaruh Pengawasan dan Kepatuhan terhadap Penggunaan Alat Pelindung Diri pada Perawat dalam Pencegahan Infeksi Nosokomial di Rumah Sakit Umum daerah Kisaran. Medan : Tesis Fakultas Kesehatan Masyarakat USU. 2012.

61. Putra, M. U. K. Hubungan Pengetahuan dan Sikap dengan Perilaku Penggunaan Alat Pelindung Diri pada Mahasiswa Profesi Fakultas Keperawatan Universiitas Indonesia. Depok : Skripsi Fakultas Ilmu Keperawatan UI. 2010.

62. Kotwal, A. Health Care Worker and Universal Precautions : Perceptions and Determinant of Non-Compliance. Indian Journal of Community Medicine. 2010.

63. WHO. Strategi Pencegahan dan Pengendalian Infeksi untuk Prosedur Khusus di FasilitasPelayanan Kesehatan. 2008 